Research Paper

\title{
Repression of Hexokinases II-Mediated Glycolysis Contributes to Piperlongumine-Induced Tumor Suppression in Non-Small Cell Lung Cancer Cells
}

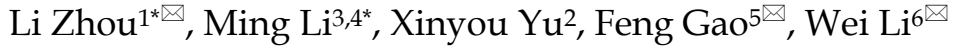 \\ 1. Department of Pathology, Xiangya Hospital of Central South University, Changsha, Hunan 410008, P.R. China \\ 2. Shandong Lvdu Bio-Industry Co., Ltd., Binzhou, Shandong 256600, P.R. China \\ 3. School of Stomatology, Hunan University of Chinese Medicine, Changsha, Hunan 410208, P.R. China \\ 4. Changsha Stomatological Hospital, Changsha, Hunan 410004, P.R. China. \\ 5. Department of Ultrasonography, The Third Xiangya Hospital of Central South University, Changsha, Hunan, 410013, P.R. China \\ 6. Department of Radiology, The Third Xiangya Hospital of Central South University, Changsha, Hunan 410013, P.R. China \\ * These authors contributed equally to this work.
}

$\triangle$ Corresponding authors: Li Zhou, Department of Pathology, Xiangya Hospital of Central South University, Changsha, Hunan 410008, P.R. China. E-mail: zhouli_723@163.com or Feng Gao, Address: Department of Ultrasonography, The Third Xiangya Hospital of Central South University, Changsha, Hunan, 410013, P.R. China. E-mail: gf0731@csu.edu.cn or Wei Li, Address: Department of Radiology, The Third Xiangya Hospital of Central South University, Changsha, Hunan 410013, P.R. China. E-mail: weililx@csu.edu.cn

(C) Ivyspring International Publisher. This is an open access article distributed under the terms of the Creative Commons Attribution (CC BY-NC) license (https://creativecommons.org/licenses/by-nc/4.0/). See http://ivyspring.com/terms for full terms and conditions.

Received: 2018.11.23; Accepted: 2019.01.21; Published: 2019.03.01

\begin{abstract}
Deregulation of glycolysis is a common phenomenon in human non-small cell lung cancer (NSCLC). In the present study, we reported the natural compound, piperlongumine, has a profound anti-tumor effect on NSCLC via regulation of glycolysis. Piperlongumine suppressed the proliferation, colony formation and HK2-mediated glycolysis in NSCLC cells. We demonstrated that exposure to piperlongumine disrupted the interaction between HK2 and VDAC1, induced the activation of the intrinsic apoptosis signaling pathway. Moreover, our results revealed that piperlongumine down-regulated the Akt signaling, exogenous overexpression of constitutively activated Aktl in HCC827 and H1975 cells significantly rescued piperlongumine-induced glycolysis suppression and apoptosis. The xenograft mouse model data demonstrated the pivotal role of suppression of Akt activation and HK2-mediated glycolysis in mediating the in vivo antitumor effects of piperlongumine. The expression of HK2 was higher in malignant NSCLC tissues than that of the paired adjacent tissues, and was positively correlated with poor survival time. Our results suggest that HK2 could be used as a potential predictor of survival and targeting HK2 appears to be a new approach for clinical NSCLC prevention or treatment.
\end{abstract}

Key words: non-small cell lung cancer, piperlongumine, glycolysis, Hexokinases II, Akt

\section{Introduction}

Non-small cell lung cancer (NSCLC) is the most common type of human lung cancer, which encompasses adenocarcinoma, squamous cell carcinoma, and large cell carcinoma. Despite advances in combinatorial therapy using both traditional chemotherapy/ radiotherapy and target therapy, the patient outcome has not improved at a satisfactory rate. Low survival is attributed to drug resistance and metastasis, and the treatment options for advanced NSCLC has limited currently [1-5]. Discovery of novel targets and development of new anti-tumor agents with fewer side effects will provide more effective strategies for NSCLC treatment.

Glucose is the energy source and the metabolic intermediate in mammalian cells. Different from normal cells, most cancer cells preferentially take glycolysis as their energy source even in the presence of oxygen. This phenomenon, which is often named 
"Warburg effect," is a new hallmark of human cancer cells [6]. Hyperactivation of glycolysis supplies a large number of intermediate for macromolecular biosynthesis. Importantly, the accumulation of lactate in tumor tissue resulted in an acidic microenvironment which is benefited for chemotherapy resistance and metastasis $[7,8]$. Hexokinase 2 is a rate-limiting enzyme which catalyzes the first committed step of glycolysis. Exception from other Hexokinase family members, HK2 is always overexpressed in human cancers. Previous studies have shown that HK2 is required for tumor initiation and maintenance, and targeting HK2 or HK2-mediated glycolysis has been recognized as a therapeutic target in multiple cancers [9-11]. Besides the acceleration of glucose uptake, mitochondrial localization of HK2 can form a complex with the pore-like protein voltage-dependent anion channel (VDAC) to maintain the mitochondrial potential and inhibits apoptosis [12]. Thus, targeting HK2 may provide a potential therapeutic target for cancer prevention and treatment.

Recently, the evidences from experimental studies have shown that piperlongumine (PL), a natural compound isolated from long pepper piper longum $\mathrm{L}$, possess multiple anti-tumor effects for a wide range of human malignancies, including lung [13], liver [14], prostate [15], breast [16], and colorectal [17] cancer. Suppression of kinase activity, regulation of the expression of the transcription factor, and dysfunction of signaling transduction were identified to be the underlying mechanisms [18]. However, there has been no study regarding the mechanisms of PL on the regulation of glycolysis in human NSCLC. In this study, we demonstrated that PL has a potential inhibitory effect on NSCLC both in vitro and in vivo. PL decreased HK2 expression, down-regulated glycolysis, and promoted mitochondrial apoptosis signaling pathway. Importantly, the Akt signaling pathway was confirmed to be crucial for piperlongumine-mediated glycolysis suppression. Overall, we evaluated the anti-tumor effects and possible mechanisms of PL on NSCLC cells.

\section{Materials and Methods}

\section{Reagents and Antibodies}

The compound piperlongumine (>99\%) was obtained from Selleck Chemicals (Houston, TX). SDS, Tris, and $\mathrm{NaCl}$ for molecular biology and buffer preparation were purchased from Sigma (St. Louis, MO). Cell culture media, FBS and supplements were from Invitrogen (Grand Island, NY). Antibodies against HK2, cleaved-PARP, cleaved-caspase 3, cytochrome C, Bax, VDAC1, p-Akt, Akt, p-S6, and S6 were purchased from Cell Signaling Technology, Inc.
(Beverly, MA). Antibody against $\beta$-actin was from Sigma. The anti-ki67 antibody was from Abcam (Cambridge, United Kingdom).

\section{Cell Culture and Transfection}

Human NSCLC cells, including H1975, H23, and HCC827 Cells were purchased from American Type Culture Collection (ATCC, Manassas, VA). The cells were cultured at $37^{\circ} \mathrm{C}$ in a humidified incubator with $5 \% \mathrm{CO}_{2}$ according to ATCC protocols. The cells were authenticated and frozen. Each vial of frozen cells was maintained no more than 10 passages. For transfection experiments, the jetPEI (Qbiogene, Inc., Montreal, Canada) transfection reagent was used following the manufacturer's instructions. The transfected cells were cultured for another 36-48 h, and whole cell lysate was extracted for further analysis.

\section{Immunoblotting and Co-immunoprecipitation (Co-IP) assays}

The whole cell lysate was extracted using the RIPA buffer (Thermo Fisher, Waltham, MA). For immunoblotting, proteins $(20 \mu \mathrm{g})$ were detected with specific primary antibodies and an HRP-conjugated secondary antibody. Antibody conjugates were visualized by the ECL chemiluminescence (Thermo Fisher). The Co-IP assays were performed as described previously [19]. Antibodies were used for immunoprecipitation: HK2, VDAC1 or normal rabbit IgG. Immunocomplexes were resolved by SDS-PAGE, and co-immunoprecipitated proteins were detected via western blot.

\section{MTS Assay}

NSCLC cells were seeded $\left(2 \times 10^{3} /\right.$ well $\left./ 100 \mu \mathrm{l}\right)$ into 96-well plates and treated with various concentrations of piperlongumine as indicated, and proliferation was assessed by MTS assay (Promega, Madison, WI) according to instructions provided.

\section{Anchorage-independent Growth Assay}

The anchorage-independent growth assays were performed as described previously [20]. Briefly, the cells were suspended $(8,000$ cells $/ \mathrm{ml})$ in $1 \mathrm{ml}$ of $0.3 \%$ agar with Eagle's basal medium containing 10\% FBS and different concentrations of piperlongumine overlaid into 6-well plates containing a $0.6 \%$ agar base. The plates were cultured in a $37^{\circ} \mathrm{C}, 5 \% \mathrm{CO}_{2}$ incubator for 2 weeks. The colony number was counted under a microscope using the Image-Pro Plus software program (Media Cybernetics, Silver Spring, MD).

\section{Flow Cytometry}

The treated cells were suspended in $1 \times 10^{6}$ cells/ml, $5 \mu \mathrm{l}$ Annexin V and Propidium Iodide were added to the cell suspension and incubated 10-15 min 
at room temperature in the dark, stained cells were assayed and quantified using a FACSort Flow Cytometer (BD, San Jose, CA, USA).

\section{Glucose Uptake and Lactate Production Measurement}

NSCLC Cells were seeded in $10-\mathrm{cm}$ plates and treated with different doses of piperlongumine for 24 h. Cells were trypsinized and seed in 6-well plates $\left(5 \times 10^{5}\right)$, after incubation for $6 \mathrm{~h}$, the medium was discarded, and cells were incubated in fresh medium for another $8 \mathrm{~h}$. Glucose and lactate levels were measured (Automatic Biochemical Analyzer; 7170A, HITACHI, Tokyo, Japan) at the Clinical Biochemical Laboratory of Xiangya Hospital (Changsha, China). The relative glucose consumption rate and lactate production rate were normalized by the protein concentration of samples.

\section{In Vivo Tumor Growth}

All the experimentation for animals was approved by the Animal Ethics Committee of Central South University. H1975 $\left(1 \times 10^{6}\right)$ or HCC827 $\left(3 \times 10^{6}\right)$ cells in $100 \mu \mathrm{L}$ RPMI-1640 were injected into the right flank of 6-week-old female athymic nude mice. The body weight of each mouse was recorded, and tumor volume was determined by vernier caliper twice a week. When the tumor volume reached $100 \mathrm{~mm}^{3}$, the mice were given an i.p. injection of piperlongumine at a dose of $10 \mathrm{mg} / \mathrm{kg}$ every two days, whereas control mice were administered vehicle. Tumor volume was calculated following the formula of $\mathrm{A} \times \mathrm{B}^{2} \times 0.5$, wherein $\mathrm{A}$ is the longest diameter of tumor, $\mathrm{B}$ is the shortest diameter, and $\mathrm{B}^{2}$ is $\mathrm{B}$ squared.

\section{Immunohistochemical Analysis of Tumor Tissue}

A human NSCLC tissue array (Hlug-NSCLC150 PT-01) from Shanghai Outdo Biotech Co., Ltd. (Shanghai, China) and included 37 cases of adenocarcinoma, 30 cases of squamous cell carcinoma, 3 cases of large cell carcinoma, 5 cases of bronchioloalveolar carcinoma and 75 cases of matched adjacent tissue. A Vectastain Elite ABC Kit (Vector Laboratories; Burlingame, CA) was used for immunohistochemical staining following the protocol. Briefly, after deparaffinized, and rehydrated, the slide was unmasked by submersion into boiling sodium citrate buffer $(10 \mathrm{mM}, \mathrm{pH} 6.0)$ for $10 \mathrm{~min}$, and then treated with $3 \% \mathrm{H}_{2} \mathrm{O}_{2}$ for $10 \mathrm{~min}$. $50 \%$ goat serum albumin in $1 \times$ PBS was used for blocking, the slides were indubated with the primary antibody at the cold room in a humidified chamber overnight. After washed and hybridized with the secondary antibody for $1 \mathrm{~h}$ at room temperature, the slides were stained using the
Vectastain Elite $\mathrm{ABC}$ kit. The intensity was estimated using Image-Pro PLUS (v.6) and Image J (NIH) software programs. Statistical analyses were performed using Prism 5.0.

\section{Statistical analysis}

Statistical analysis was performed with SPSS 16.0 (SPSS, Inc, Chicago, IL). Results expressed as mean \pm SD were analyzed using the Student's $t$ test. Differences were considered significant when $p<0.05$.

\section{Results}

\section{Piperlongumine inhibits NSCLC cells growth}

Previous studies have demonstrated that piperlongumine (Figure 1A) can act as a novel anti-tumorigenic agent in numerous types of human cancer [18]. In this study, we first tested the inhibitory effect of piperlongumine against cell proliferation in $\mathrm{H} 23$ (left), HCC827 (middle) and H1975 (right) cells. Our data indicated that low concentration of piperlongumine (2 $\mu \mathrm{m})$ had a negligible effect on cell growth inhibition. However, while the level reached over $5 \mu \mathrm{M}$, piperlongumine substantially suppressed the proliferation of NSCLC cells. Moreover, the inhibitory effect of piperlongumine was enhanced in a time-dependent manner (Figure 1B). However, piperlongumine had no inhibitory effect on the growth of normal bronchial epithelial HBE cells (Figure 1C). We then investigated the effects of piperlongumine on the anchorageindependent growth of these three NSCLC cells. As data shown in Figure 1C, piperlongumine significantly decreased the anchorage-independent growth of NSCLC cells even at the concentration of $2 \mu \mathrm{M}$. Importantly, treatment of NSCLC cells with $10 \mu \mathrm{M}$ piperlongumine almost blocked the colony formation in soft agar. These results indicate that piperlongumine suppresses the growth of NSCLC cells in a time and dose-dependent manner.

\section{Piperlongumine suppresses HK2 expression and glycolysis in NSCLC cells}

Deregulation of glycolysis is involved in the tumorigenesis of human NSCLC. Hexokinase 2, the first rate-limiting enzyme of glycolysis, is required for tumor initiation and maintenance in the mouse models of human lung cancer [9]. Based on the previous data, we then determined whether piperlongumine had any effect on HK2 expression in H23 (left), HCC827 (middle) and H1975 (right) cells. The immunoblotting data showed that the expression of HK2, but not HK1, was decreased in response to piperlongumine treatment (Figure 2 left). To further explore the efficiency of piperlongumine on glycolysis regulation, we examined the relative glucose consumption rate and lactate production rate in 
piperlongumine treated NSCLC cells. We found that accompanied by the down-regulation of HK2 protein level, piperlongumine significantly impaired the glycolytic rate in all tested NSCLC cells (Figure 2 middle and right). These results suggest that piperlongumine dose-dependently inhibits glycolysis in human NSCLC cells.

\section{Piperlongumine disrupts the interaction of HK2 and VDAC1 and induces apoptosis}

Localization of HK2 on mitochondrial confers apoptosis resistance. We further determined the interaction between HK2 and VDAC1 in HCC827 (Figure 3A, left) and H1975 (Figure 3A, left) cells. The results indicated that the endogenous binding activity of HK2 and VDAC1 were substantially decreased after treatment with piperlongumine. Because the phosphorylation of HK2 on Thr473 is required for its localization on mitochondria [21], we then determined HK2 phosphorylation in HCC827 cells. The result showed that piperlongumine significantly suppressed Thr473 phosphorylation in a dose-dependent manner (Figure 3B). We next generated the HK2 phosphomimetic T473D mutant and transfected into HCC827 cells, the co-IP data indicated that T473D compromised piperlongumine-induced the suppression of interaction between HK2 and VDAC1 (Figure 3C). Piperlongumine promoted the activation of intrinsic apoptosis signaling pathway, including the release of cytochrome $\mathrm{c}$ and Bax translocation to mitochondria (Figure 3D). As data shown in Figure $3 \mathrm{E}$, the protein levels of cleaved-PARP and -caspase 3 were significantly up-regulated in piperlonguminetreated HCC827 (Figure 3E, left), H1975 (Figure 3E, middle) and H23 (Figure 3E, right) cells. As expected, the flow cytometry data also indicated that piperlongumine induced apoptosis in HCC827 cells in a dose-dependent manner (Figure $4 \mathrm{~F}$ ), compared with the untreated group, the ratio of apoptosis cells reached to around $20 \%$. To further confirm that down-regulation of HK2 is required for the antitumor effect of piperlongumine, we constructed HK2 knock-down stable cell lines in HCC827 and H1975 cells. As data shown in Figure $3 \mathrm{G}$ and $3 \mathrm{H}$, depletion of HK2 decreased the sensitivity of NSCLC cells to piperlongumine treatment. These results suggest that piperlongumine-mediated decrease of mitochondrialassociated HK2 is related to apoptosis upregulation.

\section{Akt inhibition is required for piperlongumine-mediated glycolysis suppression in NSCLC cells}

To further explore the underlying mechanism, we determined the modulation of signaling pathway in piperlongumine-treated NSCLC cells. The results showed that piperlongumine dramatically impaired the phosphorylation of Akt, as well as the activation of downstream target $\mathrm{S} 6$ in a dose-dependent manner in HCC827 (Figure 4A, left), H1975 (Figure 4A, middle) and H23 (Figure 4A, right) cells. Importantly, treatment with the Akt signaling pathway inhibitor, wortmannin, also suppressed the activation of Akt and decreased the protein level of HK2 and glycolysis in HCC827 (Figure 4B) and H1975 cells (Figure 4C). We next transfected constitutively activated Akt1 (myr-Akt1) into HCC827 and H1975 cells. The results showed that overexpression of myr-Akt1 significantly promoted the protein level of HK2, and rescued the deficient glucose consumption and lactate production in piperlongumine-treated HCC827 (Figure 4D) and H1975 (Figure 4E) cells. Moreover, myr-Akt1 transfection rescued piperlongumine-induced apoptosis in HCC827 (Figure 4F, left) and H1975 (Figure 4F, right) cells. To understand the molecular mechanism underlying how Akt upregulates HK2, we examined HK2 mRNA level in piperlongumine-treated NSCLC cells by real-time PCR. HK2 mRNA expression was dramatically decreased in piperlongumine-treated cells (Figure 4G). Previous studies have demonstrated that the GSK3 $\beta$-FBW7 axis is crucial for the degradation of c-Myc [22]. Our data showed that piperlongumine inhibited the phosphorylation of GSK3 $\beta$ on Ser9 and decreased the protein level of c-Myc (Figure $4 \mathrm{H})$. To determine the role of c-Myc in HK2 regulation, we overexpressed c-Myc in HCC827 cells. Western blot result showed that high expression of c-Myc rescued piperlongumine-mediated down-regulation of HK2, but not the p-Akt and p-GSK3 $\beta$ (Figure 4I), indicating c-Myc is a crucial downstream target of Akt-GSK3 $\beta$ and is required for HK2 expression. These results imply that piperlongumine-mediated modulation of glycolysis and apoptosis in human NSCLC cells are partly dependent on the suppression of Akt activation.

\section{Piperlongumine inhibits tumor growth in the xenograft mouse model}

We then examined the in vivo antitumor effects of piperlongumine using a human NSCLC xenograft. HCC827 or H1975 cells were injected (s.c.) into the right flank of six-week-old female athymic nude mice. Piperlongumine treatment was initiated when the tumors were established around $100 \mathrm{~mm}^{3}$. Results indicated that in HCC827 xenograft model, the average tumor size of the vehicle-treated group was $498 \pm 112 \mathrm{~mm}^{3}$, whereas average tumor size of the piperlongumine -treated group was $197 \pm 43 \mathrm{~mm}^{3}$ (Figure 5A). The similar inhibitory effect of piperlongumine also observed in H1975 xenograft mouse model, the tumor volume of vehicle-treated and piperlongumine-treated groups were $635 \pm 143 \mathrm{~mm}^{3}$ 
and $285 \pm 63 \mathrm{~mm}^{3}$, respectively (Figure 5B). The average tumor weights of the piperlongumine-treated group were significantly smaller than those in the vehicle-treated group in both HCC827 (Figure 5C) and H1975 (Figure 5D) tumor-bearing mice. Moreover, during the treatment period, piperlongumine did not affect the body weight of the mice (Figure 5E and $5 \mathrm{~F}$ ). Tissue samples were taken from several organs, including the liver, lung, kidneys, and spleen of piperlongumine-treated mice, revealed no pathohistological changes (data not shown).

A<smiles>COc1cc(/C=C/C(=O)N2CCC=CC2=O)cc(OC)c1OC</smiles>

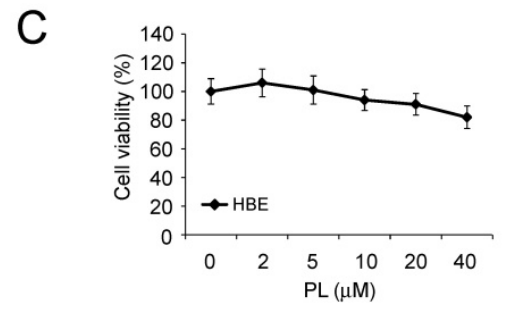

B
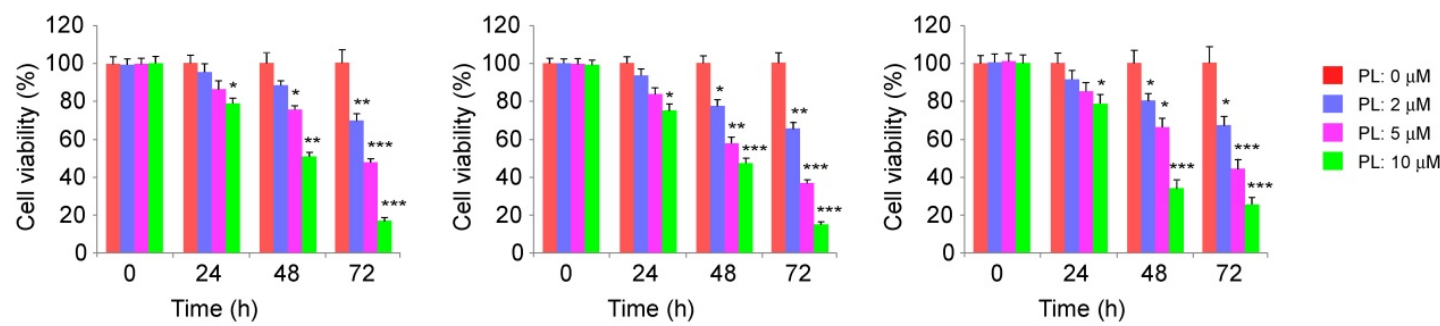

D
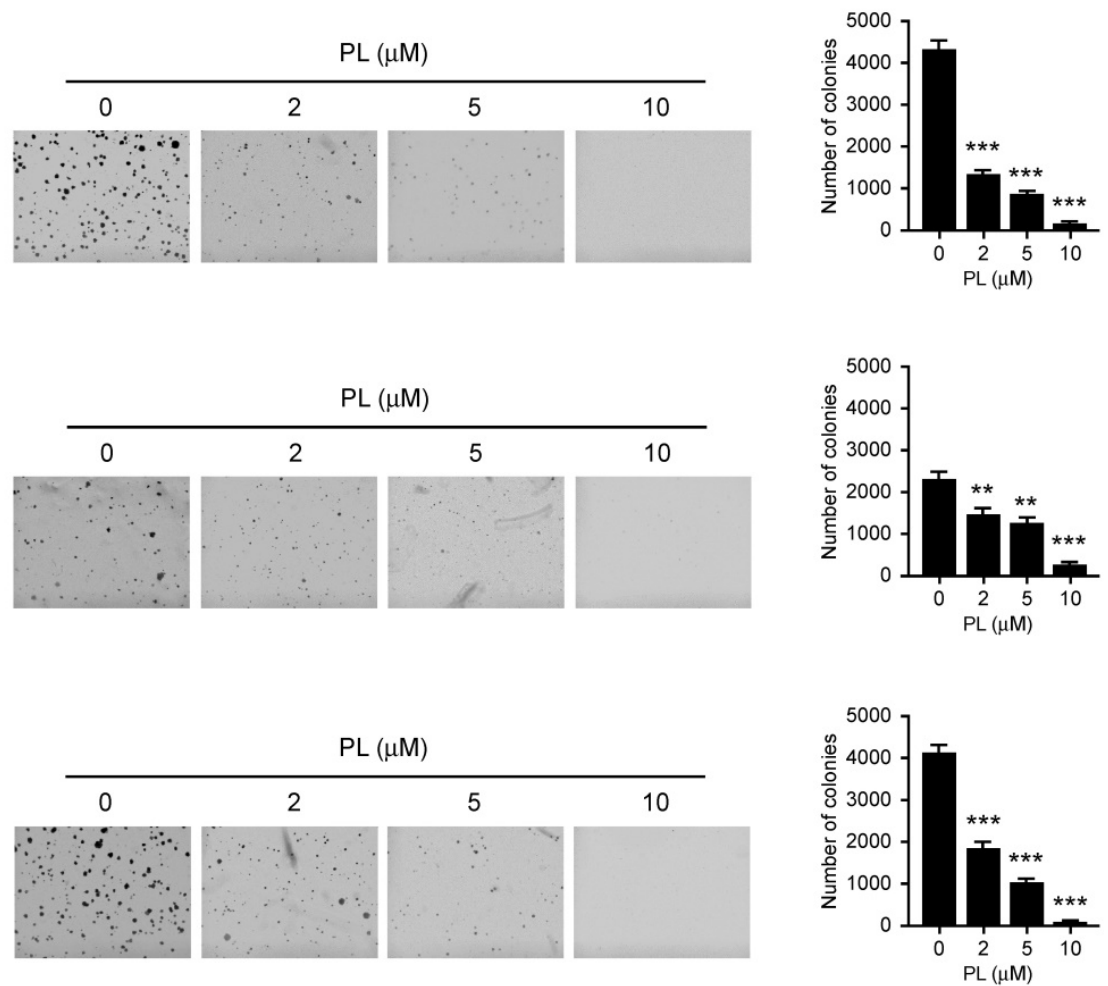

Figure 1. Inhibitory effects of piperlongumine on NSCLC cells. A, the chemical structure of piperlongumine. B, piperlongumine inhibits anchorage-dependent growth in a panel of human lung cancer cells, including H23 (left), HCC827 (middle) and H1975 (right). Cell proliferation assay was performed as described in the "Material and Methods" section. Data shown are the proliferation ability of human lung cancer cells treated with different concentrations of piperlongumine compared with the dimethyl sulfoxide-treated group. C, the effect of piperlongumine on anchorage-dependent growth of HBE cells. D, A colony formation assay was performed as described in the "Material and Methods" section. Data shown are the colony formation ability of H23 (top), HCC 827 (middle) and H1975 (bottom) cells treated with different concentrations of piperlongumine compared with the dimethyl sulfoxide-treated group. The average colony number was calculated from three separate experiments. Asterisk, significant $\left(* p<0.01\right.$, $*_{p}^{*}<0.01$, $\left.*^{* *} p<0.001\right)$ suppression of colony formation by piperlongumine compared with $\mathrm{DMSO}$ treated group. PL, Piperlongumine. 
A

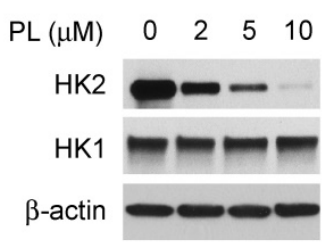

B

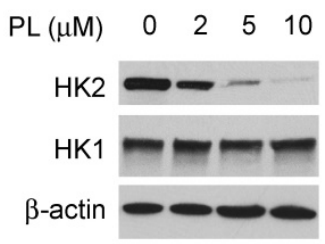

C
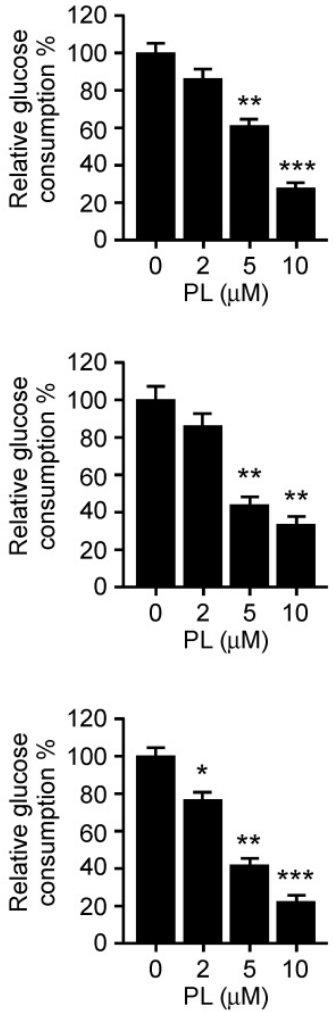
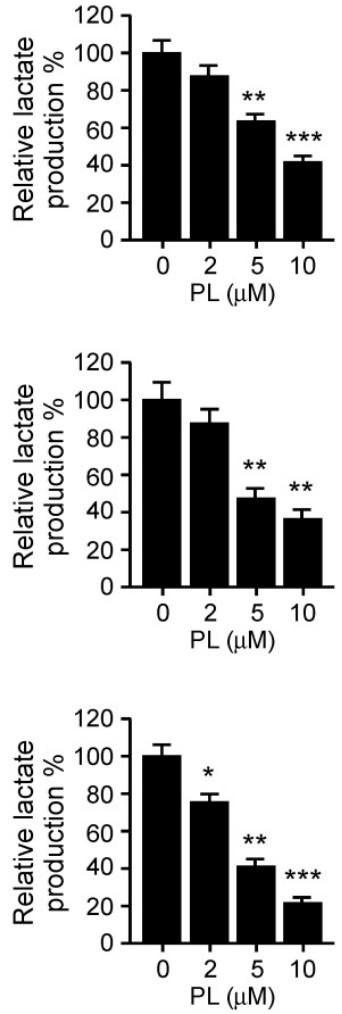

Figure 2. Piperlongumine regulates glycolysis in NSCLC cells. NSCLC cells, including H23 (A), HCC827 (B) and H1975 (C) were treated with different concentrations of piperlongumine for $24 \mathrm{~h}$. Western blotting was performed to detect HK2 expression (left). The levels of glucose consumption (middle) and lactate production (right) were examined in these cells. Columns, mean of the number of colonies as determined from three independent experiments; bars, standard deviation; asterisk, significant $\left(* p<0.05, *^{*} p<0.01, *^{* *} p<0.001\right)$ suppression of HK2 expression or glycolysis by piperlongumine compared with DMSO treated group. PL, Piperlongumine.

Additionally, immunohistochemical staining analysis of piperlongumine-treated HCC827 xenograft tumors was conducted to evaluate the expression level of p-Akt, p-S6, HK2, VDAC1, and Ki-67. Our data showed that the positive staining of p-Akt, p-S6, $\mathrm{HK} 2$, and Ki-67 were significantly suppressed in the piperlongumine-treated group compared with the vehicle-treated group (Figure 5G). These results demonstrated a pivotal role of suppression of Akt activation and HK2-mediated glycolysis in mediating the in vivo antitumor effects of piperlongumine.

\section{HK2 is over-expressed in NSCLC and positively correlated with poor patient outcomes}

To further support the role that HK2 is involved in the regulation of tumorigenesis of NSCLC, the expression of HK2 was examined by IHC in NSCLC tissue and the normal adjacent tissues, using tissue microarray. Our data showed that HK2 is overexpressed in NSCLC tissues compared with the adjacent tissue (Figure 6A). To further extend our observations to a clinicopathologically relevant context, we performed Kaplan-Meier survival analysis of HK2 with an online tool (http://kmplot.com/analysis/). The results showed that higher HK2 expression was associated with a worse Overall Survival (Figure 6B, OS, $\mathrm{P}=7.3 \mathrm{e}-0.6$ ), while there was no significant difference in First Progression (Figure 6C, FP, $\mathrm{P}=0.058$ ) and Post Progression Survival (Figure 6D, PPS, $P=0.15$ ) of NSCLC patients. These data indicate that HK2 could be used as a potential predictor of survival.

\section{Discussion}

Lung cancer still represents one of the most common and fatal neoplasms, accounting for nearly $30 \%$ of all cancer-related deaths [23]. Over $85 \%$ of all lung cancers diagnosis are NSCLC. Each year, roughly 1.3 million new cases of NSCLC are diagnosed worldwide, and only less than $25 \%$ being suitable for surgery [24, 25]. Current therapeutic protocols for NSCLC are based on chemo/ radiotherapy or target therapy regimens focusing on histology and targeted agents for patients with specific gene mutations, such as epidermal growth factor receptor (EGFR) and re-arranged anaplastic lymphoma kinase (ALK) [26-28]. However, many patients with NSCLC do not achieve durable and stable disease control, and survival rates are still low. Therefore, it is of utmost importance to develop treatment designs that ensure prolonged disease control without serious adverse events. 
A

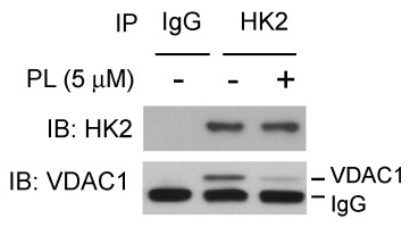

IP IgG VDAC1

$\mathrm{PL}(5 \mu \mathrm{M}) \stackrel{-}{-\quad+}$

IB: HK2

IB: VDAC1 $\approx=-{ }_{\lg } \mathrm{VAC1}$

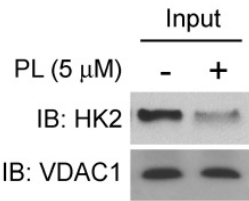

$\mathrm{PL}(5 \mu \mathrm{M}) \frac{\mathrm{IgG}}{-} \frac{\mathrm{HK} 2}{-+}$

IB: HK2

IB: VDAC1 -VDAC1

IP IgG VDAC1

$\mathrm{PL}(5 \mu \mathrm{M}) \overline{-}-+$

IB: HK2 - -

IB: VDAC1 $2=2=\frac{V D A C 1}{\lg G}$

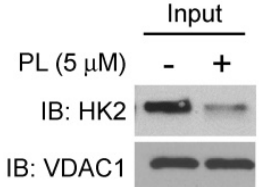

$E$

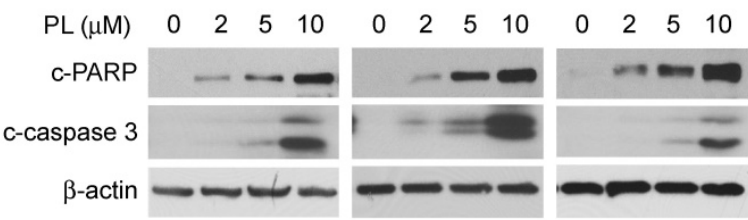

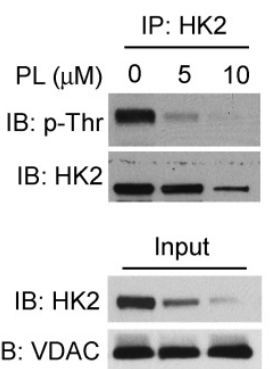

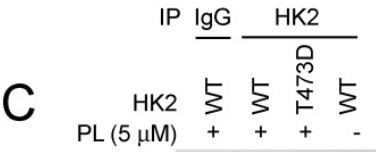

IB: VDAC

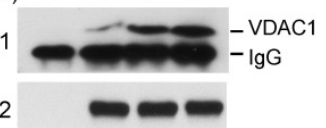

IB: HK2

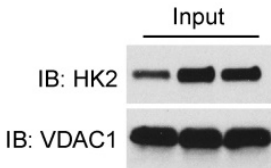

D

$\begin{array}{lllllllll}\mathrm{PL}(\mu \mathrm{M}) & 0 & 2 & 5 & 10 & 0 & 2 & 5 & 10\end{array}$ cytochrome C $\longrightarrow$
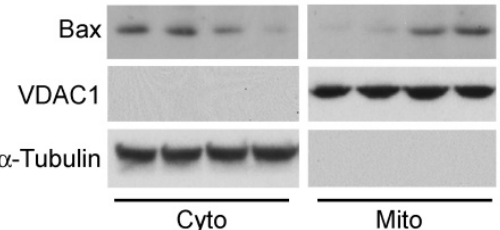

Mito
$\mathrm{PL}(\mu \mathrm{M}) \quad 0 \quad 2 \quad 5 \quad 10$ cytochrome $\mathrm{C}$

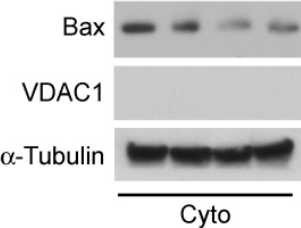

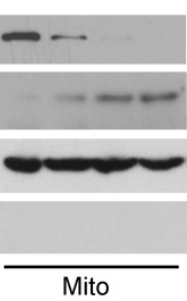

F

PL $(\mu \mathrm{M})$
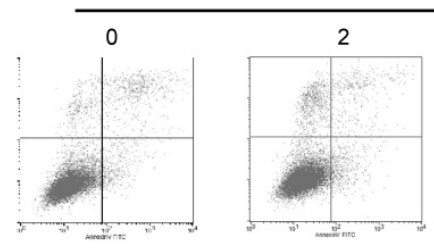

10

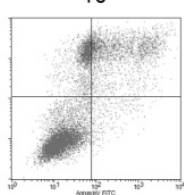

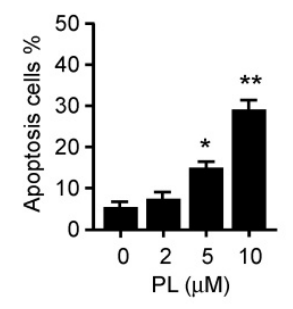

G

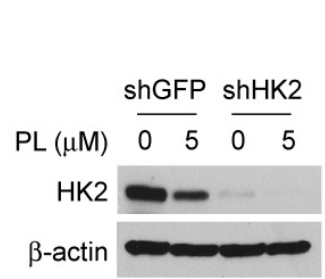

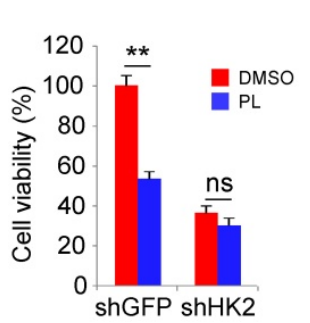

$\mathrm{H}$

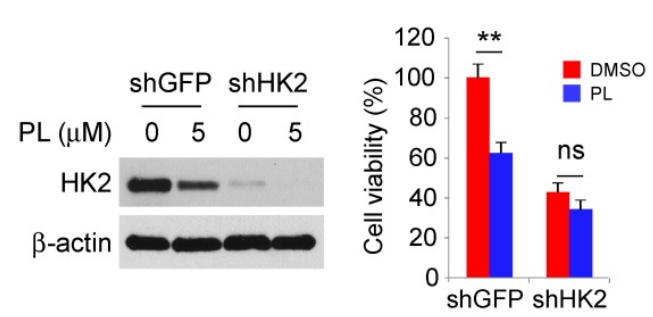

Figure 3. Piperlongumine disrupts the interaction of HK2 and VDACl and induces apoptosis. A, HCC827 (left) and $\mathrm{H} 1975$ (right) cells were treated with piperlongumine for $24 \mathrm{~h}$, co-immunoprecipitation was conducted to detect the interaction between HK2 and VDACl. B, HCC827 cells were treated with piperlongumine for $24 \mathrm{~h}$, co-immunoprecipitation and western blot were performed to identify the phosphorylation of HK2. C, HK2-WT or HK2-T473D was transfected into $\mathrm{HCC} 827$ cells, the co-immunoprecipitation and western blot were conducted to determine the interaction between HK2 and VDACl as indicated. D, HCC827 (left) and H1975 (right) cells were treated with piperlongumine for $24 \mathrm{~h}$, cytosolic fractions and mitochondrial fractions were isolated, western blot was conducted to detect the target proteins as indicated. E, HCC827 (left) and H1975 (right) cells were treated with piperlongumine for 24 h, the whole cell extract was subjected to western blot analysis as indicated. F, HCC827 (left) and H1975 (right) cells were treated with piperlongumine for 24 h, the flow cytometry was conducted for apoptosis analysis. PL, Piperlongumine. G and H, HCC827 (G) and H1975 (H) stable cells were treated with piperlongumine for 48 h, western blot and MTS assay were conducted. Asterisk, significant $\left(* p<0.05, *^{*} p<0.01\right)$ difference between groups as indicated. ns, not statistically significant. 


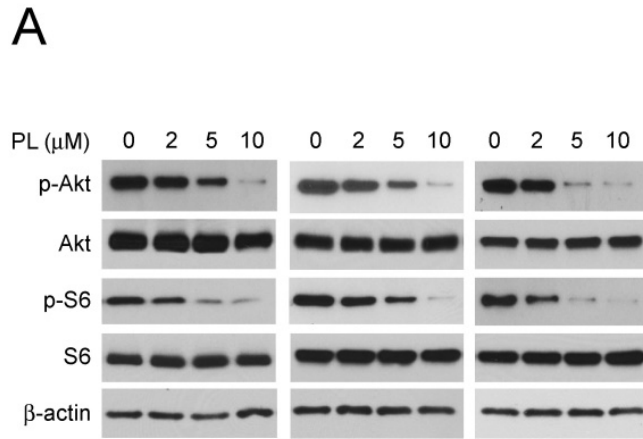

B

\section{C}

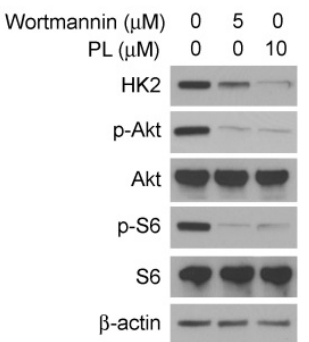

$$
\begin{array}{r}
(\mu \mathrm{M}) \quad 0 \quad 0 \quad 10 \\
\mathrm{HK} 2 \\
\text { p-Akt } \\
\text { Akt } \\
\text { p-S6 } \\
\text { S6 } \\
\beta \text {-actin }
\end{array}
$$
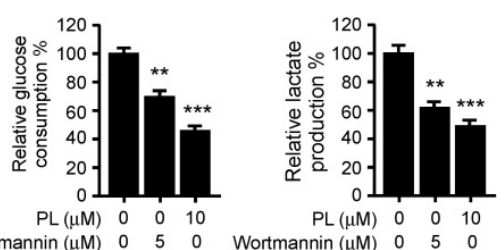

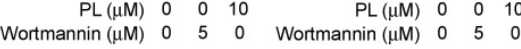

$E$
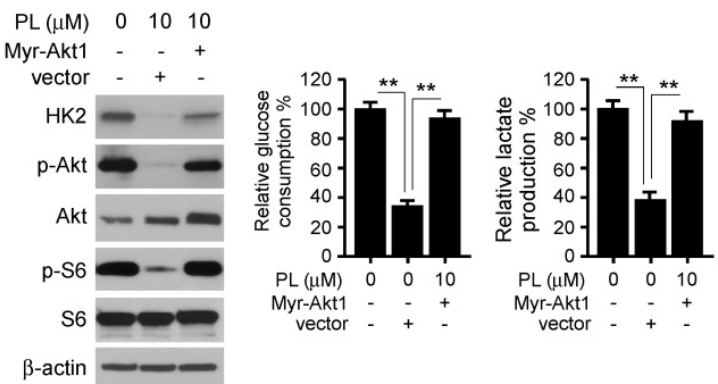

G

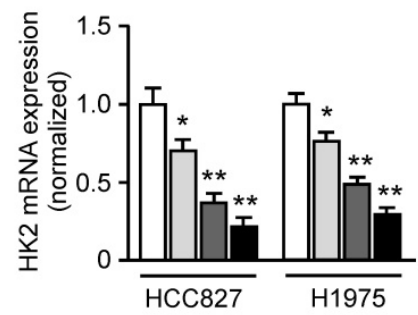

F

$\mathrm{H}$
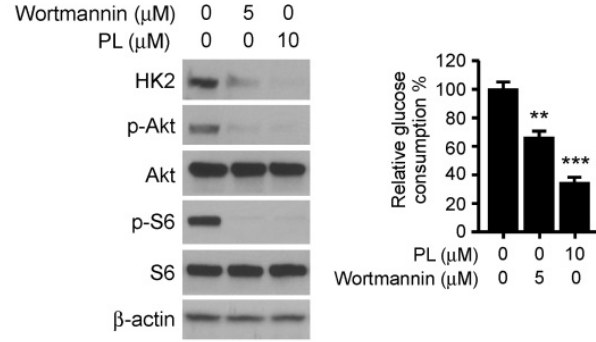

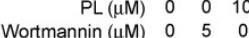

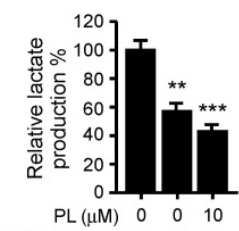

Wortmannin $(\mu \mathrm{M})$ )
PL $(\mu \mathrm{M}) \quad 0 \quad 10 \quad 10$

Myr-Akt1 - - +

vector - + -

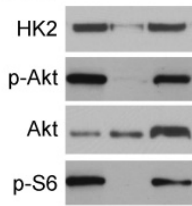

$\mathrm{p}-\mathrm{S} 6=$

S6

$\beta$-actin --
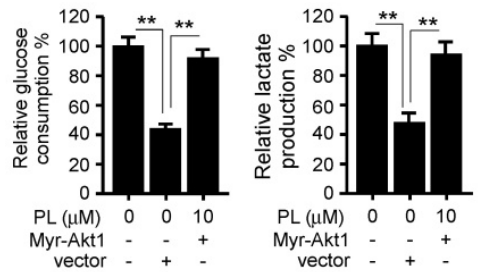
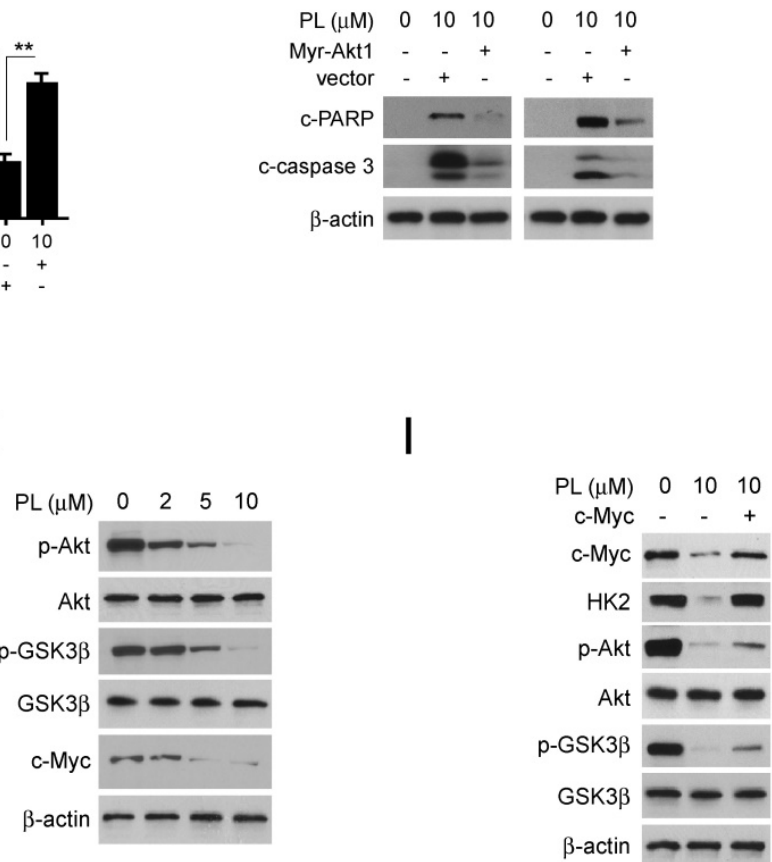

Figure 4. Down-regulation of Akt signaling is required for piperlongumine-mediated glycolysis suppression. A, HCC827 (left), $\mathrm{H} 1975$ (middle) and $\mathrm{H} 23$ cells were treated with piperlongumine for $24 \mathrm{~h}$, western blot was conducted to detect the target proteins as indicated. B and C, HCC827 (B) and H1975 (C) cells were treated with piperlongumine or wortmannin for $24 \mathrm{~h}$, the whole cell extract was subjected to western blot analysis as indicated, glucose consumption and lactate production were measured as described in the "Material and Methods" section. D and E, HCC827 (D) and H1975 (E) cells were Transient transfected with Myr-Aktl or vector, $24 \mathrm{~h}$ later, the transfected cells were treated with piperlongumine for another $24 \mathrm{~h}$. Then the cells were seeded into 6 -well plate at the concentration of $5 \times 105 /$ well, and cultured for another $12 \mathrm{~h}$. The western blot was conducted to detect the target proteins, and glucose consumption and lactate production were measured as indicated. F, HCC827 cells were treated as described in Figure 4D, and western blot was conducted to detect the cleaved-PARP and -caspase 3. G, Real-time RT-PCR analysis of total HK2 mRNA levels in $\mathrm{HCC} 827$ and $\mathrm{H} 1975$ cells. $\mathrm{H}, \mathrm{HCC} 827$ cells were treated with piperlongumine, western blot was conducted to detect the target proteins as indicated. $\mathrm{H}, \mathrm{HCC} 827$ cells were transfected with c-Myc and treated with piperlongumine for $24 \mathrm{~h}$, western blot was performed to identify the target proteins as indicated. Asterisk, significant $\left({ }^{*} p<0.01,{ }^{* *} p<0.01,{ }^{* * *} p<0.001\right)$ suppression of glycolysis by piperlongumine compared with DMSO treated group or Akt transfected group. PL, Piperlongumine. 
A

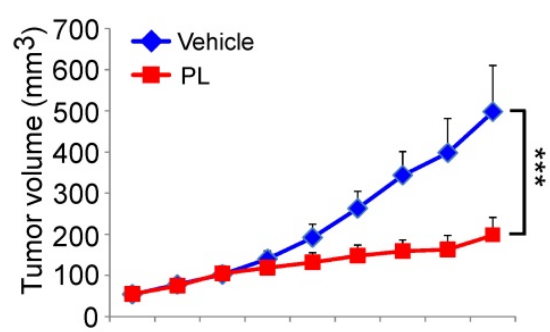

$\begin{array}{lllllllll}18 & 21 & 24 & 28 & 31 & 34 & 37 & 40 & 43\end{array}$

Days after injection

C

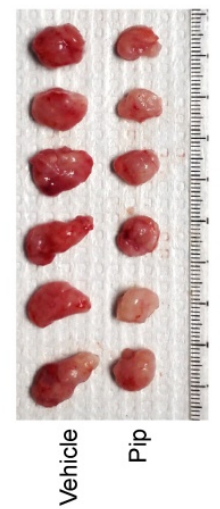

E
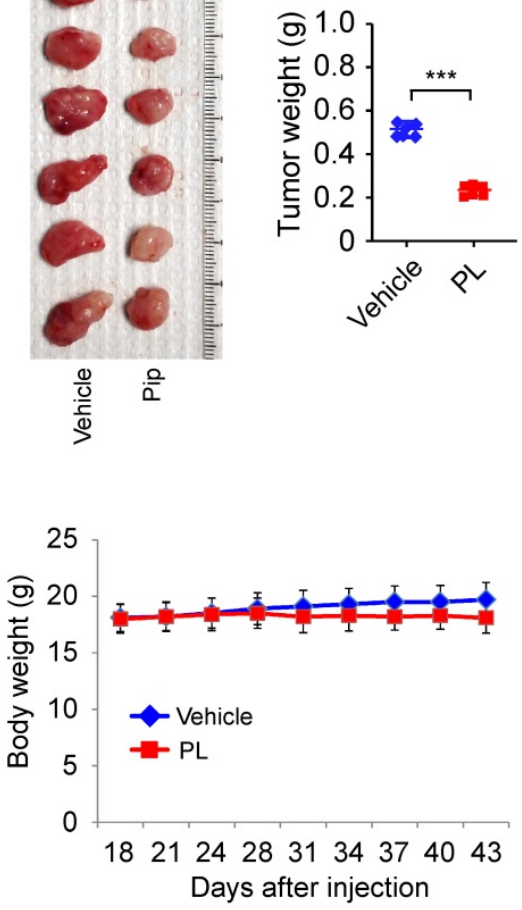

B

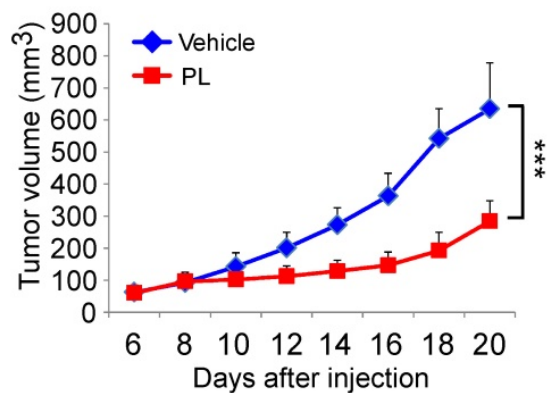

D
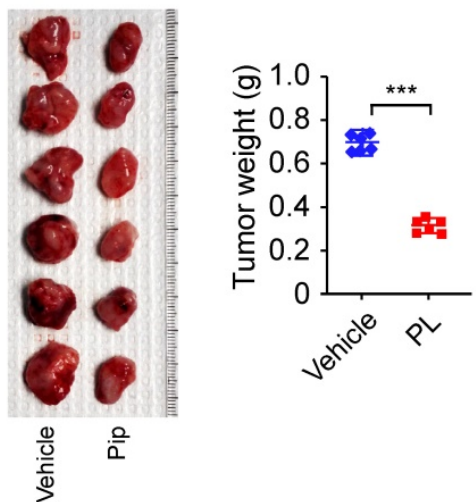

F

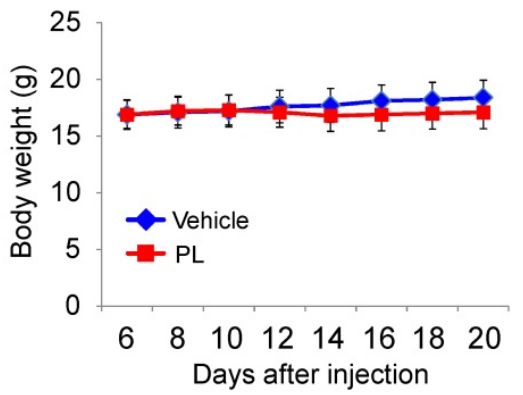

G

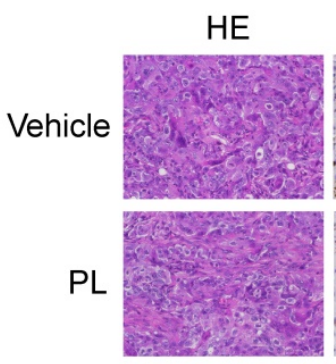

Ki67

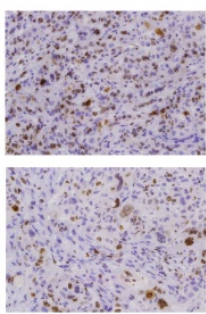

p-Akt

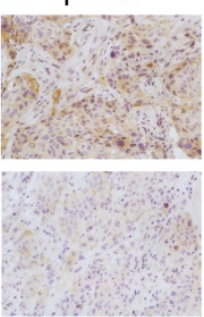

p-S6

HK2

VDAC1
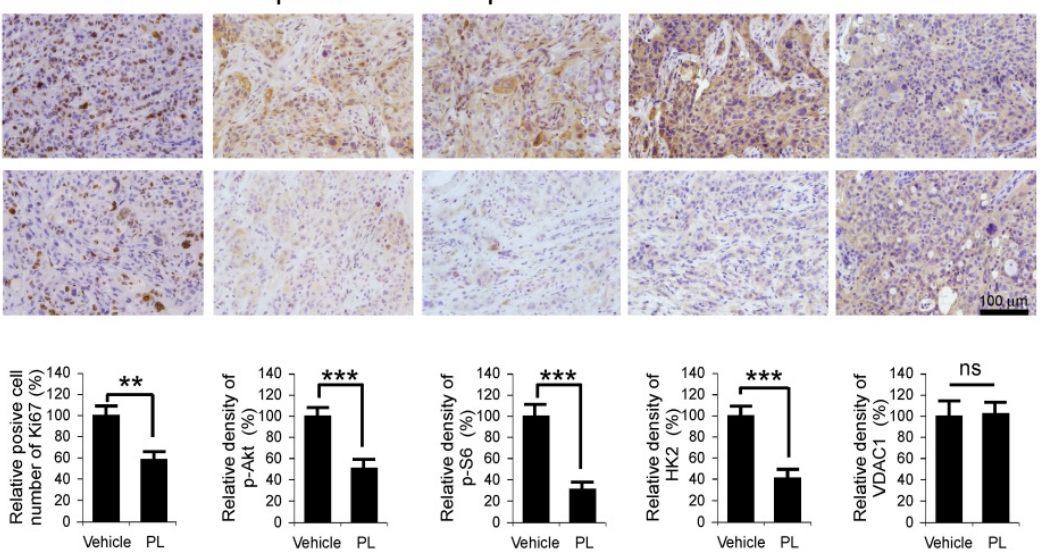

Figure 5. Piperlongumine inhibits tumor growth in NSCLC xenograft mouse models. A and B, the tumor volumes of HCC827 (A) and H1975 (B) xenograft were measured twice a week. C and D, at the treatment endpoint, the HCC827 (C) and H1975 (D) tumor-bearing mice were sacrificed, and tumors were removed, photographed and weighed. E and F, during the treatment period, the body weight of $\mathrm{HCC} 827$ (E) and H1975 (F) tumor-bearing mice were measured twice a week to determine the toxicity of piperlongumine. For A-E, data are shown as mean values \pm S.D. obtained from 6 mice in each group. E. Immunohistochemical staining detection of Ki67, p-Akt, p-S6, VDACl, and HK2 in tumor sections from Piperlongumine or vehicle-treated group mice. All panels are of the same magnification. The integrated optical density (IOD) was evaluated using the Image-Pro Plus software (version 6.2) program. Data are shown as mean values \pm S.D. Asterisk, significant $(* p<0.05, * * p<0.01, * * *<<0.001$, ) suppression of tumor growth between piperlongumine- and vehicle-treated group. PL, Piperlongumine. 
A
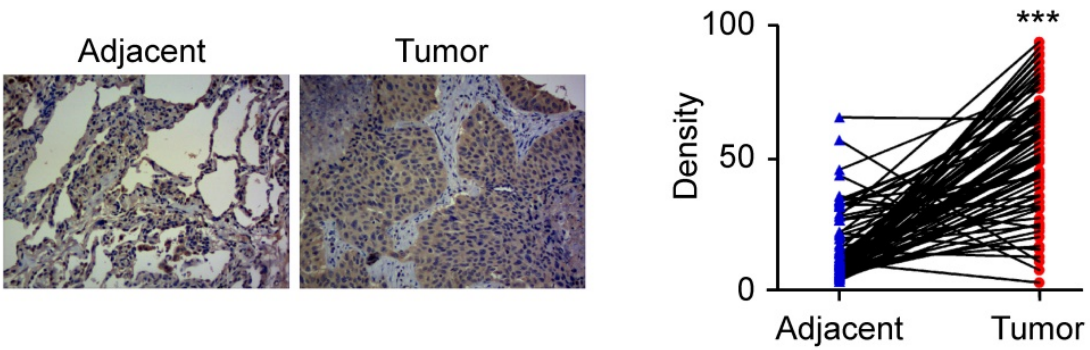

B

C
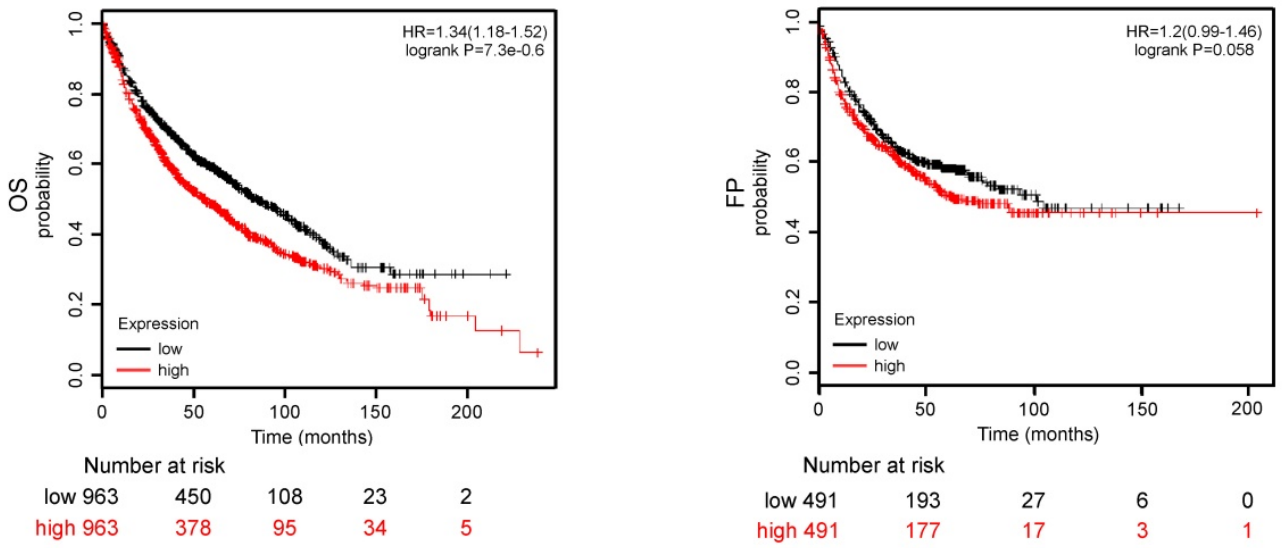

Number at risk

low $491 \quad 193$

high 491

193
177

$\begin{array}{lll}27 & 6 & 0 \\ 17 & 3 & 1\end{array}$

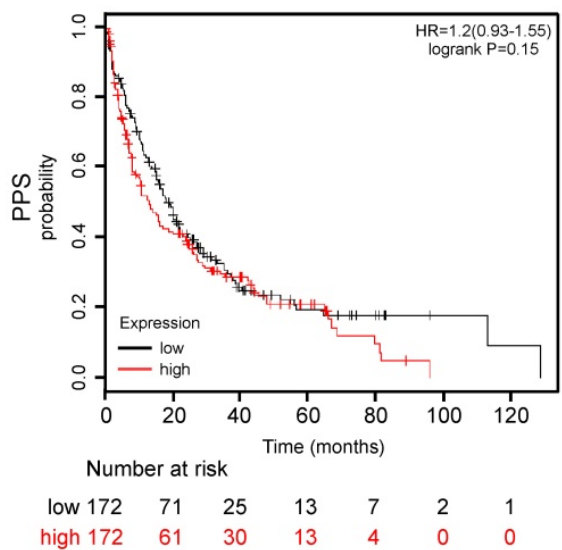

Figure 6. HK2 is over-expressed in NSCLC and positively correlated with poor patient outcomes. A, Immunohistochemical staining was performed on a lung cancer tissue array using the HK2 antibody. The intensity was evaluated using Image-Pro PLUS (v.6) and Image J (NIH) computer software. The representative image (left) and density of each sample (right) are shown. The asterisk indicates a significant difference (***p $<0.001$, Mann-Whitney $U$-test) between tumor and adjacent tissue as indicated. B-D, Kaplan-Meier survival analysis for the relationship between survival time and HK2 signature in NSCLC was performed by using the online tool (http://kmplot.com/analysis/). B, OS, Overall Survival. C, FP, First Progression Survival. D, PPS, Post Progression Survival. $p<0.05$ was considered to be a statistically significant difference.

In contrast to the small molecule through rational chemical design, natural products have more potential to be applied to tumor chemotherapy owing to their structural diversity. Recently, numerous natural compounds have been demonstrated exerting anti-tumor activity through the suppression of cell cycle progression, impairment of angiogenesis, induction of apoptosis, and inhibition of glycolysis
[20, 29-34]. Piperlongumine is an amide alkaloid constituent of the Piper longum L. (long piper), which is also named as piplartine and used as an Ayurvedic medicine for a long time. Over the past decades, PL was reported to possess diverse biological activities, including anti-nociceptive, anti-depressant, neuroprotective, and especially, anti-tumor properties. Induction of cell cycle arrest and apoptosis, 
suppression of migration and metastasis, and restriction of angiogenesis were reported to be the underlying mechanisms in PL-mediated anti-tumor activity $[18,35]$. PL induces G2/M phase arrest in cholangiocarcinoma and gastric carcinoma [36, 37], promotes apoptosis in colon cancer in a p53dependent manner [38], inhibits the migration and metastasis in glioblastoma and other types of human cancer cells [39-41]. Despite the anti-tumor activity of PL being studied in the past decade, the underlying mechanism, especially the anti-tumor effect in NSCLC, remains limited. Here, we found that PL had profound potency against NSCLC in vitro and in vivo via down-regulation of glycolysis. For the first time, we discovered that, with the suppression of HK2, the glucose consumption and lactate production in NSCLC cells was markedly inhibited after PL treatment.

Hyperactivation of glycolysis is a hallmark of cancer and is closely correlated with the dysfunction of glycolytic enzymes, such as GLUT1, HK-2, and PKM2 [42]. Increased HK2 expression is associated with poor patient survival in colon cancer, hepatocellular carcinoma, and glioblastoma [43, 44], and targeting HK2, and HK2-mediated glycolysis suppressed tumor cell growth in a panel of human cancer types. Up-regulation of glycolytic enzymes was found to be in NSCLC tissue and cell lines [45-47]. Here, we found that HK2 is overexpressed in human NSCLC tissue, using the online tool (http:// kmplot. com/analysis/) analysis, we further confirmed that up-regulation of HK2 is positively correlated with poor patient outcomes in NSCLC (Figure 6).

Akt signaling plays a crucial role in the regulation of cancer cell metabolism, especially the glycolysis. Loss of PTEN or mutation of the PIK3CA gene, which result in the constitutive activation of Akt in NSCLC, promotes cancer cell growth, survival, and confer resistance to chemo/radiotherapy or targeted therapy [48-50]. Previous studies have demonstrated that Akt signaling is required for maintaining of HK2 expression [51]. However, the regulation of HK-2 in cancer cells is complicated. The expression level of HK2 is dominantly controlled by the oncogenic pathways, including PI3K/Akt, c-myc, NF-kB, and HIF-1a [52-55]. In the present study, we found that accompanied by the inhibition of Akt activation, PL significantly suppressed the expression of HK2. Overexpression of constitutively activated Akt1 partly rescued PL-mediated glycolysis suppression, which suggested that disturbance of other oncogenic pathways also involved in PL-induced HK2 regulation. Although PL processes the potential in decreasing the activity of c-Myc and NF-kB $[56,57]$, the underlying mechanisms and details correlated to HK2 regulation in NSCLC need further illumination.

Translocation to the mitochondrial outer membrane and interacts with the pore-like protein voltage-dependent anion channel (VDAC) to maintain the mitochondrial potential is required for HK2-promoted cancer cell survival [12, 58]. Our data showed that PL significantly inhibited the interaction between HK2 and VDAC1, and promoted the activation of mitochondrial apoptosis signaling pathway in NSCLC cells. Recent studies have demonstrated that overexpression of HK2 was involved in chemotherapy resistance in human cancers. Given the effect of PL on HK-2, which may further help us to understand the mechanism why PL has the synergistic effect to promote the anti-tumor effect of chemotherapy drugs, such as cisplatin and 5-Fu $[59,60]$. Briefly, the present study identified PL as a novel therapeutic agent to regulate glycolysis in NSCLC cells and could provide a new option for clinical combination treatment of NSCLC.

\section{Acknowledgements}

This work was supported by the Natural Science Foundation of Hunan Province (2018JJ2604, 2018JJ37 87), and Science and Technology Program Project Funds of Changsha (kq1701018).

\section{Competing Interests}

The authors have declared that no competing interest exists.

\section{References}

1. Schildgen $\mathrm{V}$, Schildgen $\mathrm{O}$. The lonely driver or the orchestra of mutations? How next generation sequencing datasets contradict the concept of single driver checkpoint mutations in solid tumours - NSCLC as a scholarly example. Semin Cancer Biol. 2018.

2. Rosenzweig KE, Gomez JE. Concurrent Chemotherapy and Radiation Therapy for Inoperable Locally Advanced Non-Small-Cell Lung Cancer. J Clin Oncol. 2017; 35: 6-10.

3. Chan BA, Hughes BG. Targeted therapy for non-small cell lung cancer: current standards and the promise of the future. Transl Lung Cancer Res. 2015; 4: 36-54.

4. Sini C, Tuzi A, Rossi G, Russo A, Pezzuto A. Acquired resistance in oncogene-addicted non-small-cell lung cancer. Future Oncol. 2018; 14: 29-40.

5. Dickhoff C, Otten RHJ, Heymans MW, Dahele M. Salvage surgery for recurrent or persistent tumour after radical (chemo)radiotherapy for locally advanced non-small cell lung cancer: a systematic review. Ther Adv Med Oncol. 2018; 10: 1758835918804150.

6. Hanahan D, Weinberg RA. Hallmarks of cancer: the next generation. Cell. 2011; 144: 646-74.

7. Anderson M, Marayati R, Moffitt R, Yeh JJ. Hexokinase 2 promotes tumor growth and metastasis by regulating lactate production in pancreatic cancer. Oncotarget. 2017; 8: 56081-94.

8. Li XB, Gu JD, Zhou QH. Review of aerobic glycolysis and its key enzymes new targets for lung cancer therapy. Thorac Cancer. 2015; 6: 17-24.

9. Patra KC, Wang Q, Bhaskar PT, Miller L, Wang Z, Wheaton W, et al Hexokinase 2 is required for tumor initiation and maintenance and its systemic deletion is therapeutic in mouse models of cancer. Cancer Cell. 2013; 24: 213-28.

10. Akins NS, Nielson TC, Le HV. Inhibition of Glycolysis and Glutaminolysis: An Emerging Drug Discovery Approach to Combat Cancer. Curr Top Med Chem. 2018; 18: 494-504.

11. Mair R, Wright AJ, Ros S, Hu DE, Booth T, Kreis F, et al. Metabolic Imaging Detects Low Levels of Glycolytic Activity That Vary with Levels of c-Myc Expression in Patient-Derived Xenograft Models of Glioblastoma. Cancer Res. 2018; 78: 5408-18. 
12. Krasnov GS, Dmitriev AA, Lakunina VA, Kirpiy AA, Kudryavtseva AV. Targeting VDAC-bound hexokinase II: a promising approach for concomitant anti-cancer therapy. Expert Opin Ther Targets. 2013; 17: 1221-33.

13. Zheng J, Son DJ, Gu SM, Woo JR, Ham YW, Lee HP, et al. Piperlongumine inhibits lung tumor growth via inhibition of nuclear factor kappa B signaling pathway. Sci Rep. 2016; 6: 26357.

14. Chen Y, Liu JM, Xiong XX, Qiu XY, Pan F, Liu D, et al. Piperlongumine selectively kills hepatocellular carcinoma cells and preferentially inhibits their invasion via ROS-ER-MAPKs-CHOP. Oncotarget. 2015; 6: 6406-21.

15. Kim YH, Yoon YJ, Lee YJ, Kim CH, Lee S, Choung DH, et al. Piperlongumine derivative, CG-06, inhibits STAT3 activity by direct binding to STAT3 and regulating the reactive oxygen species in DU145 prostate carcinoma cells. Bioorg Med Chem Lett. 2018; 28: 2566-72.

16. Jin HO, Park JA, Kim HA, Chang YH, Hong YJ, Park IC, et al. Piperlongumine downregulates the expression of HER family in breast cancer cells. Biochem Biophys Res Commun. 2017; 486: 1083-9.

17. Sharkey CC, Li J, Roy S, Wu Q, King MR. Two-stage nanoparticle delivery of piperlongumine and tumor necrosis factor-related apoptosis-inducing ligand (TRAIL) anti-cancer therapy. Technology (Singap World Sci). 2016; 4: 60-9.

18. Piska K, Gunia-Krzyzak A, Koczurkiewicz P, Wojcik-Pszczola K, Pekala E. Piperlongumine (piplartine) as a lead compound for anticancer agents Synthesis and properties of analogues: A mini-review. Eur J Med Chem. 2018; 156: 13-20.

19. Li W, Yu X, Ma X, Xie L, Xia Z, Liu L, et al. Deguelin attenuates non-small cell lung cancer cell metastasis through inhibiting the CtsZ/FAK signaling pathway. Cell Signal. 2018; 50: 131-41.

20. Li W, Yu X, Xia Z, Yu X, Xie L, Ma X, et al. Repression of Noxa by Bmi1 contributes to deguelin-induced apoptosis in non-small cell lung cancer cells. J Cell Mol Med. 2018; 22: 6213-27.

21. Roberts DJ, Tan-Sah VP, Smith JM, Miyamoto S. Akt phosphorylates HK-II at Thr-473 and increases mitochondrial HK-II association to protect cardiomyocytes. J Biol Chem. 2013; 288: 23798-806.

22. Welcker M, Orian A, Jin J, Grim JE, Harper JW, Eisenman RN, et al. The Fbw7 tumor suppressor regulates glycogen synthase kinase 3 phosphorylation-dependent c-Myc protein degradation. Proc Natl Acad Sci U S A. 2004; 101: 9085-90.

23. Agustoni F, Suda K, Yu H, Ren S, Rivard CJ, Ellison K, et al. EGFR-directed monoclonal antibodies in combination with chemotherapy for treatment of non-small-cell lung cancer: an updated review of clinical trials and new perspectives in biomarkers analysis. Cancer Treat Rev. 2018; 72: 15-27.

24. Rotow J, Bivona TG. Understanding and targeting resistance mechanisms in NSCLC. Nat Rev Cancer. 2017; 17: 637-58.

25. Pao W, Chmielecki J. Rational, biologically based treatment of EGFR-mutant non-small-cell lung cancer. Nat Rev Cancer. 2010; 10: 760-74.

26. Loong HH, Kwan SS, Mok TS, Lau YM. Therapeutic Strategies in EGFR Mutant Non-Small Cell Lung Cancer. Curr Treat Options Oncol. 2018; 19: 58.

27. Melosky B, Cheema P, Agulnik J, Albadine R, Bebb DG, Blais N, et al. Canadian perspectives: update on inhibition of ALK-positive tumours in advanced non-small-cell lung cancer. Curr Oncol. 2018; 25: 317-28.

28. Asao T, Takahashi F, Takahashi K. Resistance to molecularly targeted therapy in non-small-cell lung cancer. Respir Investig. 2018.

29. Li W, Gao F, Ma X, Wang R, Dong X, Wang W. Deguelin inhibits non-small cell lung cancer via down-regulating Hexokinases II-mediated glycolysis. Oncotarget. 2017; 8: 32586-99.

30. Zhou Y, Li M, Yu X, Liu T, Li T, Zhou L, et al. Butein suppresses hepatocellular carcinoma growth via modulating Aurora B kinase activity. Int J Biol Sci. 2018; 14: $1521-34$.

31. Li W, Yu X, Tan S, Liu W, Zhou L, Liu H. Oxymatrine inhibits non-small cell lung cancer via suppression of EGFR signaling pathway. Cancer Med. 2018; 7: 208-18.

32. Yu X, Liang Q, Liu W, Zhou L, Li W, Liu H. Deguelin, an Aurora B Kinase Inhibitor, Exhibits Potent Anti-Tumor Effect in Human Esophageal Squamous Cell Carcinoma. EBioMedicine. 2017; 26: 100-11.

33. Yu X, Li W, Deng Q, You S, Liu H, Peng S, et al. Neoalbaconol inhibits angiogenesis and tumor growth by suppressing EGFR-mediated VEGF production. Mol Carcinog. 2017; 56: 1414-26.

34. Li M, Yu X, Li W, Liu T, Deng G, Liu W, et al. Deguelin suppresses angiogenesis in human hepatocellular carcinoma by targeting HGF-c-Met pathway. Oncotarget. 2018; 9: 152-66.

35. Bezerra DP, Pessoa C, de Moraes MO, Saker-Neto N, Silveira ER, Costa-Lotufo LV. Overview of the therapeutic potential of piplartine (piperlongumine). Eur J Pharm Sci. 2013; 48: 453-63.

36. Thongsom S, Suginta W, Lee KJ, Choe H, Talabnin C. Piperlongumine induces $\mathrm{G} 2 / \mathrm{M}$ phase arrest and apoptosis in cholangiocarcinoma cells through the ROS-JNK-ERK signaling pathway. Apoptosis. 2017; 22: 1473-84.

37. Zhang B, Shi X, Xu G, Kang W, Zhang W, Zhang S, et al. Elevated PRC1 in gastric carcinoma exerts oncogenic function and is targeted by piperlongumine in a p53-dependent manner. J Cell Mol Med. 2017; 21: 1329-41.

38. F DASM, Munari FM, Scariot FJ, Echeverrigaray S, Aguzzoli C, Pich CT, et al. Piperlongumine Induces Apoptosis in Colorectal Cancer HCT 116 Cells Independent of Bax, p21 and p53 Status. Anticancer Res. 2018; 38: 6231-6.

39. Lee HL, Hwang SC, Nah JW, Kim J, Cha B, Kang DH, et al. Redox- and pH-Responsive Nanoparticles Release Piperlongumine in a Stimuli-Sensitive
Manner to Inhibit Pulmonary Metastasis of Colorectal Carcinoma Cells. J Pharm Sci. 2018; 107: 2702-12.

40. Song X, Gao T, Lei Q, Zhang L, Yao Y, Xiong J. Piperlongumine Induces Apoptosis in Human Melanoma Cells Via Reactive Oxygen Species Mediated Mitochondria Disruption. Nutr Cancer. 2018; 70: 502-11.

41. Liu QR, Liu JM, Chen Y, Xie XQ, Xiong XX, Qiu XY, et al. Piperlongumine inhibits migration of glioblastoma cells via activation of ROS-dependent p38 and JNK signaling pathways. Oxid Med Cell Longev. 2014; 2014: 653732.

42. $\mathrm{Yu} \mathrm{L}$, Chen $\mathrm{X}$, Wang L, Chen S. The sweet trap in tumors: aerobic glycolysis and potential targets for therapy. Oncotarget. 2016; 7: 38908-26.

43. Wu J, Hu L, Wu F, Zou L, He T. Poor prognosis of hexokinase 2 overexpression in solid tumors of digestive system: a meta-analysis. Oncotarget. 2017; 8: 32332-44.

44. Wolf A, Agnihotri S, Micallef J, Mukherjee J, Sabha N, Cairns R, et al. Hexokinase 2 is a key mediator of aerobic glycolysis and promotes tumor growth in human glioblastoma multiforme. J Exp Med. 2011; 208: 313-26.

45. Suzuki S, Okada M, Takeda H, Kuramoto K, Sanomachi T, Togashi K, et al. Involvement of GLUT1-mediated glucose transport and metabolism in gefitinib resistance of non-small-cell lung cancer cells. Oncotarget. 2018; 9: 32667-79.

46. Goodwin J, Neugent ML, Kim JW. Lung squamous cell carcinoma exhibits a targetable glucose dependency unique among non-small cell lung cancers. Mol Cell Oncol. 2017; 4: e1364211.

47. Papadaki C, Sfakianaki M, Lagoudaki E, Giagkas G, Ioannidis G, Trypaki M, et al. PKM2 as a biomarker for chemosensitivity to front-line platinum-based chemotherapy in patients with metastatic non-small-cell lung cancer. Br J Cancer. 2014; 111: 1757-64.

48. Sos ML, Koker M, Weir BA, Heynck S, Rabinovsky R, Zander T, et al. PTEN loss contributes to erlotinib resistance in EGFR-mutant lung cancer by activation of Akt and EGFR. Cancer Res. 2009; 69: 3256-61.

49. Sawa K, Koh Y, Kawaguchi T, Kambayashi S, Asai K, Mitsuoka S, et al. PIK3CA mutation as a distinctive genetic feature of non-small cell lung cancer with chronic obstructive pulmonary disease: A comprehensive mutational analysis from a multi-institutional cohort. Lung Cancer. 2017; 112: 96-101.

50. Vestergaard $\mathrm{HH}$, Christensen MR, Lassen UN. A systematic review of targeted agents for non-small cell lung cancer. Acta Oncol. 2018; 57: 176-86.

51. Roberts DJ, Miyamoto S. Hexokinase II integrates energy metabolism and cellular protection: Akting on mitochondria and TORCing to autophagy. Cell Death Differ. 2015; 22: 248-57.

52. Kim JW, Gao P, Liu YC, Semenza GL, Dang CV. Hypoxia-inducible factor 1 and dysregulated c-Myc cooperatively induce vascular endothelial growth factor and metabolic switches hexokinase 2 and pyruvate dehydrogenase kinase 1. Mol Cell Biol. 2007; 27: 7381-93.

53. Masoud GN, Li W. HIF-1alpha pathway: role, regulation and intervention for cancer therapy. Acta Pharm Sin B. 2015; 5: 378-89.

54. Dang CV, Le A, Gao P. MYC-induced cancer cell energy metabolism and therapeutic opportunities. Clin Cancer Res. 2009; 15: 6479-83.

55. Londhe P, Yu PY, Ijiri Y, Ladner KJ, Fenger JM, London C, et al. Classical NF-kappaB Metabolically Reprograms Sarcoma Cells Through Regulation of Hexokinase 2. Front Oncol. 2018; 8: 104.

56. Kim N, Do J, Bae JS, Jin HK, Kim JH, Inn KS, et al. Piperlongumine inhibits neuroinflammation via regulating NF-kappaB signaling pathways in lipopolysaccharide-stimulated BV2 microglia cells. J Pharmacol Sci. 2018; 137: 195-201.

57. Wang Y, Wu X, Zhou Y, Jiang H, Pan S, Sun B. Piperlongumine Suppresses Growth and Sensitizes Pancreatic Tumors to Gemcitabine in a Xenograft Mouse Model by Modulating the NF-kappa B Pathway. Cancer Prev Res (Phila). 2016; 9: 234-44.

58. Majewski N, Nogueira V, Bhaskar P, Coy PE, Skeen JE, Gottlob K, et al. Hexokinase-mitochondria interaction mediated by Akt is required to inhibit apoptosis in the presence or absence of Bax and Bak. Mol Cell. 2004; 16: 819-30.

59. Roh JL, Kim EH, Park JY, Kim JW, Kwon M, Lee BH. Piperlongumine selectively kills cancer cells and increases cisplatin antitumor activity in head and neck cancer. Oncotarget. 2014; 5: 9227-38.

60. Liu Q, Zhao D, Zhu X, Chen H, Yang Y, Xu J, et al. Coloaded Nanoparticles of Paclitaxel and Piperlongumine for Enhancing Synergistic Antitumor Activities and Reducing Toxicity. J Pharm Sci. 2017; 106: 3066-75. 